\title{
Application Research of BIM Technology in Project Cost Management in the Era of Big Data
}

\author{
Bing Chen ${ }^{a}$, Pengyue Wang, Lijinyu Bi \\ Shenyang Jianzhu University, Shenyang, 110168, China \\ a373556955@qq.com
}

\begin{abstract}
In the era of big data, BIM technology has been widely applied in project cost management. The feasibility of applying BIM technology in project cost management in the era of big data is studied. Using BIM technology to manage project cost and apply it to every specific stage can effectively improve the efficiency of project cost management and promote the healthy and benign development of project cost management.
\end{abstract}

Keywords: The Era of Big Data; BIM Technology; Project Cost Management.

\section{Introduction}

Building Information model (Building Information Modeling), hereinafter referred to as BIM. The application of building information model to engineering cost management can effectively improve the effect of engineering cost, and the application of the provided data to the enterprise's engineering projects can effectively improve the final quality of engineering management.In the era of big data, the application of BIM technology in project cost management can realize the sharing of project cost data resources, facilitate the communication and cooperation between various parties, and promote the quality management of project cost with both quality and quantity guaranteed.

\section{Overview}

\subsection{Overview of the Age of Big Data}

Nowadays, big data and "Internet +" have made people's pace of life faster and faster. Big data not only brings convenience to people's life, but also improves their quality of life. The most obvious characteristics of the era of big data are the huge amount of data, fast transmission of information, pictures and documents, accurate data analysis and high timeliness of data. The processor of big data requires fast operation speed, which has greatly improved the work efficiency. In addition, big data can store a large amount of information of all kinds, breaking the way of information storage in the past.

\subsection{Overview of BIM Technology}

BIM technology is to use the digital form, establish the corresponding model with the help of the Internet, and perfectly display the relationship between each part of the building and each other through the Internet. In project cost management, BIM technology is warmly welcomed and widely used. As for BIM technology itself, it has the advantages of strong visualization, strong simulation, strong coordination and easy drawing, etc., and it can establish $3 \mathrm{~d}$ models of buildings on the Internet.

\subsection{Overview of Project Cost Management}

Process cost management refers to the management of the project budget and actual expenditure, which is embodied in the decision-making stage, design stage, bidding stage and implementation stage of the project. Project cost management can ensure the project decision-making and design more accurate, can effectively control the entire project funds. 


\section{Feasibility Analysis on the Application of BIM Technology in Project Cost Management in the Era of Big Data}

\subsection{Realize the Project Cost Data Resource Sharing}

In the project cost management, a large number of data will be generated. In the previous project cost management, data confusion or data loss is easy to occur. Through the application of BIM technology, data management and sharing can be easily realized, such as storing indicators, specific data and content of each project, establishing database and perfecting corresponding electronic database, so as to facilitate the future search and use. BIM technology can realize the sharing of data resources in the project cost management, significantly improve the work efficiency of the project cost management, avoid problems and loopholes in manual operation, ensure the accuracy of data, and effectively improve the effectiveness of the project cost management.

\subsection{Facilitate the Communication and Cooperation between the Parties}

BIM technology can establish data information model according to the corresponding requirements, carry out rational analysis of human resources, carry out scientific and reasonable planning for the construction and design stage, accurately design and budget the entire project amount and all materials and engineering costs required by the project. The project plan tends to be perfect presentation, accurate budget of the project volume and cost, to ensure the smooth implementation of the project. The application of BIM technology is based on the Internet technology. With the help of the Internet platform, project parties can timely communicate with each other at the same time, and all departments can realize real-time consultation in all aspects of project planning, design, construction and decision-making. This kind of communication and cooperation between various parties can effectively improve the quality of the whole project and ensure the overall progress and efficiency of the project. BIM technology can realize the perfect communication between various departments of project cost management, realize the optimal allocation and reasonable arrangement of resources, accurately calculate the various human, financial and material resources needed in specific construction stages, and improve the utilization rate of funds and materials.

\subsection{Improve the Quality of All-dimensional Project Cost Management}

BIM technology can include the design and construction stages of the whole project into the data information model and realize the cost management of the whole process. Through BIM technology, the leadership can clearly and intuitively understand the overall progress and specific situation of the whole project, and provide timely feedback on the waste of resources and construction errors in the specific construction process. The management is familiar with the implementation of the whole project, and then accurately calculate the construction schedule of the whole project, to complete the project in time, quality and quantity. In addition, BIM technology can understand the cost of the whole project, ensure the economic benefits of the project, and conduct technical monitoring of the cost of the whole project.

\subsection{Change the Project Cost Management Mode}

The application of BIM technology in project cost management can change the original passive mode of project cost management into active mode of management. By accurate analysis of information data, dynamic tracking analysis of project cost can be carried out. The resources used in the whole project can be displayed intelligently through data, and the cost management of the project can be effectively improved with the help of network data calculation method. At the same time, BIM technology can track the progress of the project in real time and give timely feedback. For example, the financial department can analyze the costs incurred by the construction project, compare the expected economic benefits, and analyze the deficiencies in the process of the construction project through economic difference. In addition, BIM technology realizes information verification before, 
during and after the implementation of engineering projects through whole-process management, to ensure the overall construction process and the final economic benefits.

\section{Application of BIM Technology in Project Cost Management in the Era of Big Data}

\subsection{Application of Project Investment Decision Stage}

In the traditional engineering investment decision, there are more or less certain problems in the estimation of construction engineering, which leads to the deviation of the estimation of engineering price from the actual situation and the phenomenon of low economic benefit or zero economic benefit finally appears. There are some problems in the standard and set of investment estimation methods in the past, so it is difficult to ensure the accurate evaluation and prediction of engineering projects, and a series of problems occur in the estimation of engineering projects, which bring unnecessary troubles and serious economic losses to the development of construction enterprises. Therefore, in order to accurately estimate the whole project, a construction enterprise can apply BIM technology in the investment decision-making stage of the project, and summarize and integrate the information of the whole project through the data and information modeling of BIM technology, Accurate calculation of the relevant information of the project cost, and then by the project cost management personnel for a second accounting and appropriate adjustment, the project cost can be accurately estimated. In addition, if there are problems when the project cost management staff carries out the investment budget, they can also extract the data from the BIM database established to ensure the accuracy of the whole project investment budget and improve the efficiency of the project cost budget. BIM technology can also solve the problem that construction enterprises cannot accurately compare investment schemes, which is a difficult problem for construction enterprises in project investment estimation. Using computer, BIM technology can easily retrieve relevant data resources from the database, and then provide the most reasonable investment scheme and design and construction scheme for construction enterprises through data comparison and collation, which not only saves human resources, but also ensures the accuracy of investment scheme.

\subsection{Application in the Project Design Phase}

The management of project design also belongs to the category of project cost management. Construction projects include the initial design stage of the whole project, the technical design stage of construction, and then the design stage of construction drawings. These stages also include budget estimates for project design, construction revisions and construction drawings. In the course of previous construction projects, project staff had to plan to determine the preliminary design and construction technical design, which was time-consuming and could not ensure the accuracy of the results. Therefore, BIM technology is used to change the working mode of construction enterprises, carry out reasonable modeling, calculate the amount of work and get the accurate project cost. When designing construction drawings, BIM technology is used to establish the model and design the construction drawings to ensure the consistency between the construction drawings and the actual construction effect. to solve the problem of discrepancy between the previous construction drawing and the actual construction, to ensure the effectiveness of project cost management. Therefore, the application of BIM technology in the project design stage can improve the rationality and accuracy of the project design, improve the overall project cost management efficiency, and avoid unnecessary problems caused by inaccurate project design.

\subsection{Application of Project Bidding Stage}

In China, construction engineering projects are mostly selected through bidding. One of the problems is that the two parties differ greatly in project valuation. In the final process of project valuation, the bidding and tendering parties spend a lot of time, personnel and material force, and 
may not reach an agreement due to the inconsistency of information between the two parties. BIM technology can effectively solve this problem, so as to ensure the accuracy of project valuation information of both parties. Using BIM technology to extract corresponding data resources in the database, design a sound and reasonable project valuation data report according to the specific requirements of both parties. This not only saves the working time of both parties, but also improves the working efficiency, ensures the accuracy of project valuation of both parties, perfectly solves the problem of difference of project valuation between both parties, and improves the working efficiency of project cost management.

\subsection{Application in the Construction Stage of the Project}

In the past, construction enterprises carried out construction according to the contract signed by both parties. After the completion of the construction task, they provided the tenderee with the specific construction situation and specific bill items. the tenderee shall entrust professionals to conduct final acceptance of the project, and only after the acceptance is passed will settlement be made to the construction enterprise. However, in this process, the project cost is often too high, or due to too many project cost management personnel, resulting in the inconsistency between the project cost and the actual fund, which will increase the time of acceptance and check, affecting the normal settlement of balance payment. the 5D modeling technology of BIM can perfectly solve these problems. 5D modeling is established based on $3 \mathrm{~d}$ model, adding two dimensions of construction schedule and project cost to form a 5D model. this model enables enterprises to intuitively understand the specific situation of engineering construction, and adjust according to the actual situation, running through all links of the whole project. During the delivery with the tenderee, the funds of each stage will be directly displayed. Even if there is any inconsistency between the actual situation and the project cost, the tenderee can clearly see which link the project cost has increased and formulate a reasonable balance payment settlement method.

\subsection{Application at the Completion Stage of the Project}

In the past, problems and mistakes were easy to occur in the completion stage of a project. The settlement of the completion of the project affects the project cost management, in the settlement, to check the project quantity. Project cost management personnel mostly check and compare every detail of the project construction through drawings and budget work books. This stage will spend a lot of time and energy, and there will be some deviations in labor more or less. BIM technology can perfectly solve this problem. Project cost management personnel can directly check the data in the BIM database, carry out completion settlement of construction projects, reduce the checking time, improve work efficiency, and ensure the accuracy of settlement data.

\section{References}

[1] Hu Yuqi, Chen Xuhong. Discussion on the application of BIM technology in construction Engineering Cost management [J]. Value Engineering, 202, 39 (1): 252-254.

[2] Zhong Weihua. Application research of BIM Technology in project Cost management [J]. Building Materials and Decoration, 2020 (2): 159-160.

[3] Iyan Ping. Application analysis of BIM Technology in Project Cost management [J]. Sichuan Cement, 2019 (6): 341. 